\title{
Inteligencias y sabidurías organizacionales: Redes de conocimiento en torno al aprendizaje de la complejidad
}

\author{
Organizational intelligences and wisdoms: Knowledge \\ networks focus on learning complexity
}

\section{(1) PSiCOGENTE EISSN 2027-212X}

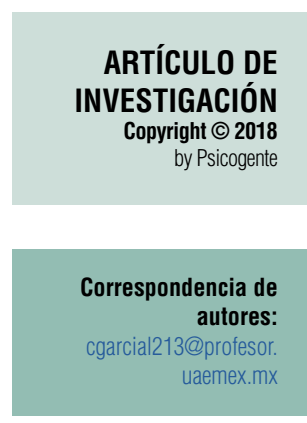

Recibido: 17-04-17 Aceptado: $16-05-18$ Publicado: 08-01-19

\section{Inteligências organizacionais e sabedoria: redes de conhecimento em torno da aprendizagem da complexidade}

\author{
Cruz García Lirios iD \\ Universidad Autónoma del Estado de México, Nezahualcóyotl, México
}

Resumen

Objetivo: Explicar el desempeño de una red de conocimiento, entendida desde la psicología de la inclusión como un sistema de gestión, producción y transferencia entre las demandas del entorno y las capacidades de la organización.

Método: Se realizó un estudio no experimental, transversal y correlacional con una selección muestral no probabilística de 300 administrativos, docentes y estudiantes de una universidad pública, considerando su interacción en prácticas profesionales. Se utilizó la Escala de Complejidad Organizacional de García (2016), la cual es una síntesis de 1) Inventario de Estrategias de Pensamiento (Torkamani \& Mahmoudi, 2016) 2) Escala de Inteligencia Competitiva (Saleh, Rahimi \& Amirnejad, 2015); 3) Cuestionario de Aprendizaje Organizacional (Erfani \& Jafari, 2013), los cuales se procesaron con la técnica Delphi.

Resultados: El grado de aprendizaje de la red de conocimiento siguió un patrón selectivo, ya que las posibles combinaciones de las redes de conocimiento sugieren que la capa de entrada al estar regulada por la capa intermedia refleja, en la capa de salida, una gestión, producción y transferencia de conocimiento en función de las tareas más que de los objetivos o las metas. Se advierte la emergencia de una inteligencia organizacional centrada en cuatro factores: Autorregulación, disipación, adaptabilidad y dinamismo.

Conclusión: Se advierten líneas de investigación alusivas a las posibles relaciones entre factores tales como la motivación al logro, la utilidad esperada o la facilidad de llevar a cabo una tarea en red como determinantes del clima de tareas, principal factor emergente de la red de conocimiento.

Palabras clave: Valores intangibles, Redes de conocimiento, Inteligencia organizacional, Aprendizaje de la complejidad

Abstract

Objective: To explain the performance of a knowledge network, understood as a system of management, production and transfer between the demands of the environment and the capabilities of the organization.

Method: A non-experimental, cross-sectional and correlational study was carried out with a non-probabilistic sample selection of 300 administrative staff, teachers and students of a public university, considering their interaction in professional practices. The Organizational Complexity Scale de García (2016) was used, which is a synthesis of 1) Inventory of Thinking Strategies (Torkamani \& Mahmoudi, 2016); 2) Scale of Competitive Intelligence (Saleh, Rahimi \& Amirnejad, 2015); 3) Organizational Learning Questionnaire (Erfani \& Jafari, 2013) which were processed with the Delphi technique.

Results: The degree of learning of the knowledge network followed a selective pattern because, the possible combinations of the knowledge networks suggest that the input layer, when regulated by the intermediate layer, reflects in the output layer; management, production and transfer of knowledge in terms of tasks rather than objectives or goals. One can see the emergence of an organizational intelligence centered on four factors: self-regulation, dissipation, adaptability and dynamism.

Cómo citar este artículo (APA):

García Lirios, C. (2019). Inteligencias y sabidurías organizacionales: Redes de conocimiento en torno al aprendizaje de la complejidad. Psicogente 22(41),

1-28. https://doi.org/10.17081/psico.22.41.3304 
Conclusion: There are lines of research alluding to the possible relationships between factors such as the motivation to achieve, the expected utility or the ease of carrying out a network task as determinants of the task climate, the main emerging factor of the knowledge network.

Keywords: Intangible values, Knowledge networks, Organizational intelligence, Complexity learning

\section{INTRODUCCIÓN}

En este trabajo se hizo una revisión de los contextos educativos de las inteligencias y sabidurías colectivas de Surowiecky (2005) y Lévy (2004) para observar las alianzas estratégicas, las redes de conocimiento y las dimensiones complejas de aprendizaje organizacional propuestas por Carreón, Hernández, Quintero, García y Mejía (2016) mediante el establecimiento de la confiabilidad y la validez de la Escala de Inteligencia Organizacional que midió el fenómeno en una IES del centro de México.

En el marco del capitalismo informacional en general y del capital humano en particular convergen el conocimiento y la sabiduría, así como la creación, formación y consolidación de redes y se abre la discusión en torno a su inteligencia y aprendizaje organizacional. En ese sentido es que la sabiduría, entendida como un procesamiento de información asimilada y consolidada, converge con la inteligencia o la capacidad para innovar a partir de la interrelación con el entorno (González \& Váttimo, 2012).

De este modo es que el capitalismo informacional definirá a la sociedad del conocimiento como un contexto en el que los datos al estar disponibles dejarán de tener un valor, ya que desde las tecnologías de información y comunicación, principalmente Internet, serán accesibles desde cualquier dispositivo electrónico (Hasegawa, 2003).

Precisamente, la diferencia entre el capitalismo industrial y el capitalismo informacional radica en la creación del conocimiento y más precisamente en la gestión, producción y transferencia de inteligencias colectivas (véase Tabla 1).

Tabla 1.

Taxonomía de las inteligencias colectivas

\begin{tabular}{|c|c|c|}
\hline INTELIGENCIA & REDES & APRENDIZAJE \\
\hline Informática & $\begin{array}{l}\text { Procesamiento y difusión de informa- } \\
\text { ción acorde a dispositivos electrónicos } \\
\text { y sinergias sociodigitales. }\end{array}$ & $\begin{array}{l}\text { Centrado en habilidades computacionales de selección, reseña, recrea- } \\
\text { ción y difusión de datos isomórficos a una comunidad digital como los } \\
\text { grupos de Facebook, WhatsApp, Twitter, Instagram o YouTube. }\end{array}$ \\
\hline Noética & $\begin{array}{l}\text { Emotividad centrada en lógicas de } \\
\text { escasez o abundancia de recursos }\end{array}$ & $\begin{array}{c}\text { Optimización de recursos desde una lógica de escasez e innovación de } \\
\text { procesos desde una lógica de la abundancia. }\end{array}$ \\
\hline Sabiduría & $\begin{array}{l}\text { Reflexividad con base en experiencias, } \\
\text { recursos y capacidades discursivas. }\end{array}$ & $\begin{array}{l}\text { Centrado en el diálogo y el contraste de narrativas experienciales, así } \\
\text { como la asimilación de principios orientadores del ser y su entorno. }\end{array}$ \\
\hline
\end{tabular}

Fuente: Elaborada a partir de Carreón (2016) 
En el contexto de las inteligencias colectivas, entendidas como la diversificación de emisores y receptores de información, los datos no solo son accesibles y compartidos sino además, susceptibles de estructurarse en repositorios, facilitan el auto-aprendizaje y sobre todo, la autonomía (Lévy, 2004). Surowiecky (2005) advierte que en el proceso del desarrollo humano, la autonomía propiciará la diversificación de opiniones, exacerbando la toma de decisiones independientes de un centro de poder, sumando datos a una colectividad que denomina "sabiduría de las masas". Se trata de redes de conocimiento que en esencia proliferan en las instituciones educativas, principalmente la universidad pública por su composición económica, política y social.

Una red de conocimiento es un clima de tareas centrado en las relaciones de empatía, confianza, compromiso, emprendimiento, innovación y satisfacción, pero en un sentido complejo, estriba en una comunicación vertical y bidireccional, con liderazgos y seguidores mutuamente influyentes, así como un sistema de gestión y administración centrado en los talentos (Aguilar, et al., 2016).

En el marco de la globalización neoliberal, las políticas educativas se han centrado en la calidad de los procesos y los productos conforme a un sistema de evaluación, acreditación y certificación. En cada una de estas fases, quienes conforman una institución u organización dedicada a la gestión, producción y transferencia del conocimiento están sujetos a lineamientos institucionales que determinan el financiamiento, subsidio o condonación de pagos por servicios públicos (Carreón, Hernández, Morales \& García, 2014).

En la medida en que las instituciones de educación superior (IES) ajustan sus capacidades a los requerimientos estatales, circunscriben sus estrategias y funciones a una relación autocrática entre líderes y talentos al priorizar una comunicación unidireccional y motivación extrínseca, pero si estas IES compiten por recursos financieros, entonces desarrollan culturas de éxito y climas de innovación orientados a la gestión, producción y transferencia de conocimiento (Carreón, Hernández, Castillo \& García, 2015).

Incluso, la formación de redes de conocimiento está encaminada a la adquisición de ventajas competitivas derivadas de una cultura flexible, y un clima innovador y de confianza para el emprendimiento del conocimiento, siendo el compromiso y la satisfacción de talentos factores clave en el desarrollo de la organización (Carreón, Hernández, Quintero \& García, 2016). 
Empero, las organizaciones sujetas a evaluación, acreditación y certificación enfocan sus capacidades en la relación asimétrica entre sus líderes y talentos, prevaleciendo una estructura vertical de toma de decisiones. En este escenario autoritario, los talentos son asumidos como recursos o instrumentos, reduciendo sus capacidades a la ejecución de conocimientos (Carreón, Hernández, García \& Bustos, 2017).

En contraste, cuando emergen liderazgos transformacionales que delegan las decisiones a los talentos y promueven el desarrollo de sus capacidades, las organizaciones se enfocan en la producción del conocimiento más que en la reproducción y transferencia del conocimiento. Se trata de un escenario en el que la diversificación de estrategias y funciones en talentos y líderes explicaría el grado de emprendimiento e innovación, así como de compromiso y satisfacción de los actores implicados (García, 2004).

En tal panorama, el desarrollo organizacional ha sido explicado desde teorías que resaltan la importancia de las relaciones y motivaciones humanas.

La inteligencia noética, centrada en las emociones, ha sido objeto de estudio de la teoría humanista de las organizaciones. Se trata de un proceso emotivo, afectivo $y / o$ sentimental en el que el procesamiento de información se orienta hacia el beneficio de las personas ya no asumidas como medios sino consideradas más bien como fines en sí mismas, aunque la literatura advierte que se trata de un clima de relaciones susceptible a la negociación y por ende a la imposición de criterios, necesidades, intenciones y expectativas (Acar \& Acar, 2014).

De este modo, la inteligencia noética suprime a la sabiduría informática al develar los límites de la racionalidad que persigue la maximización de los beneficios y la minimización de los costos.

Es así como la inteligencia noética, centrada en las emociones asertivas, los afectos bilaterales y los sentimientos bidireccionales genera una espiral o círculo virtuoso que va de la empatía a la felicidad, transitando por la confianza, el compromiso, el emprendimiento, la cooperación, la solidaridad, la colaboración y la satisfacción (Hernández \& Valencia, 2016).

Se trata de una inteligencia noética que centra su interés en la formación de un capital social o interrelación colaborativa orientada por expresiones que generan un valor emocional a la cooperación intencional en la medida en que se aproxima a la sabiduría colectiva (Omotayo \& Adenike, 2013). 
Es en tal sentido que la inteligencia noética o emocional propicia una red de conocimiento peculiar que se distingue por su grado de disuasión y persuasión discursiva frente a las necesidades y expectativas de grupos ante un contexto de escasez de recursos o contingencias de riesgos. En tal escenario, la empatía y la confianza, el compromiso y la cooperación son disposiciones que se transforman en el capital intangible más valioso de una organización dedicada a la creación de innovaciones (Anicijevic, 2013).

La inteligencia noética o afectiva supone relaciones discretas o estructuras provisionales, relaciones esporádicas y acciones emergentes que se complementan con la sabiduría informática que consiste en el establecimiento de relaciones continuas de control, obediencia y conformidad desde liderazgos tradicionales o autocráticos, estructura vertical, comunicación unidireccional y motivación unilateral (véase Tabla 2).

Tabla 2.

Tipología de las relaciones complejas organizacionales

\begin{tabular}{|c|c|c|c|c|}
\hline & DIMENSIÓN & CONTINUIDAD & DISCRECIONALIDAD & CAPITAL \\
\hline $\begin{array}{l}\text { Sabiduría } \\
\text { Emocional }\end{array}$ & Adaptación & $\begin{array}{l}\text { Las organizaciones adaptativas empren- } \\
\text { den climas de relaciones con base en } \\
\text { sus capacidades de ajuste a los requeri- } \\
\text { mientos externos e internos. }\end{array}$ & $\begin{array}{l}\text { Las organizaciones adaptativas } \\
\text { generan procesos alternos a sus in- } \\
\text { novaciones que les permiten ajustar } \\
\text { sus objetivos y metas en función de } \\
\text { la disponibilidad de recursos y las } \\
\text { demandas del entorno. }\end{array}$ & Informacional \\
\hline $\begin{array}{c}\text { Sabiduría } \\
\text { Informática }\end{array}$ & Autorregulación & $\begin{array}{l}\text { Las organizaciones autorreguladas están } \\
\text { inmersas en un proceso de gestión, } \\
\text { producción y reproducción de conoci- } \\
\text { mientos orientado hacia el equilibrio } \\
\text { informativo. }\end{array}$ & $\begin{array}{l}\text { Las organizaciones autorreguladas } \\
\text { establecen redes de conocimiento } \\
\text { para diferenciarse o asemejarse a } \\
\text { otras organizaciones con las que } \\
\text { no tienen intercambio de saberes y } \\
\text { conocimientos. }\end{array}$ & Intelectual \\
\hline $\begin{array}{l}\text { Sabiduría } \\
\text { Colectiva }\end{array}$ & Dinamismo & $\begin{array}{l}\text { Las organizaciones dinámicas estable- } \\
\text { cen procesos de confianza, emprendi- } \\
\text { miento, innovación y satisfacción que } \\
\text { suponen una motivación constante en } \\
\text { función de los logros de objetivos y } \\
\text { consecución de metas. }\end{array}$ & $\begin{array}{l}\text { Las organizaciones dinámicas gene- } \\
\text { ran innovaciones con la finalidad de } \\
\text { establecer dos rutas de conocimiento } \\
\text { tácito e implícito en función de las } \\
\text { asimetrías entre oportunidades y } \\
\text { capacidades. }\end{array}$ & Social \\
\hline $\begin{array}{c}\text { Sabiduría } \\
\text { noética }\end{array}$ & Disipación & $\begin{array}{l}\text { Las organizaciones emergentes desa- } \\
\text { rrollan oportunidades y capacidades } \\
\text { informativas en función del control, se- } \\
\text { guimiento y motivación de sus recursos. }\end{array}$ & $\begin{array}{c}\text { Las organizaciones emergentes } \\
\text { desarrollan procesos implícitos } \\
\text { de motivación que potencializan } \\
\text { sus capacidades, aun cuando las } \\
\text { oportunidades no están definidas o } \\
\text { delimitadas. }\end{array}$ & Relacional \\
\hline
\end{tabular}

Fuente: Adaptada de Carreón et al., (2016)

Las organizaciones complejas generan equilibrio y disipación, adaptación e innovación a partir de las diferencias entre demandas y recursos. Las organizaciones complejas establecen procesos implícitos orientados al desarrollo 
de conocimientos tácitos a partir de objetivos y metas de alto riesgo (Pérez, Carreón, Quintero, Bucio, García \& Aguilar, 2016).

Las inteligencias, sabidurías, redes, capitales y relaciones discretas o continuas se observan en sus procesos e indicadores, pero sobre todo en sus relaciones de dependencia como es el caso de las redes y nodos (García, 2005). Tales relaciones pueden ser noéticas o emocionales, así como informáticas o sinergias para la transferencia de datos (Quintero, Velázquez, Sales \& Padilla, 2016). A fin de poder integrarse o fusionarse, las inteligencias, sabidurías y redes de conocimiento se orientan hacia la complejidad en la medida en que emergen nuevas relaciones o disposiciones entre sus actores (Cruz, Arroyo \& Marmolejo, 2016).

Las relaciones continuas son el reflejo de las relaciones discretas ya que, en un sentido autoorganizativo la complejidad de una organización no solo radica en su equilibrio continuo sino, además, en su equilibrio latente. Es el caso de las IES dedicadas a la formación continua de talentos, pero a la vez la producción de valores y normas que orienten la inteligencia académica hacia una sabiduría compartida (Saansongu \& Ngutor, 2012).

En el proceso que va de las relaciones continuas a las relaciones discretas, las IES con inteligencia y sabiduría se adscriben a redes, grafos y nodos. La diferencia entre cada una de estas tres instancias radica en las relaciones explícitas o transferencia de conocimiento tácito, pero sobre todo en las relaciones de conocimiento implícito (Mendoza, Ramírez \& Atriano, 2016).

Es así como las alianzas estratégicas dan lugar a las redes de conocimiento y estas originan grafos que pueden ser visualizados como institutos de colaboración multidisciplinar mediante arcos o convenios establecidos al interior de la universidad o con respecto a otros grafos (Robles, Alviter, Ortega \& Martínez, 2016).

Los arcos o relaciones entre alianzas, redes, grafos y nodos pueden ser bilaterales, mejor conocidos como díadas, o trilaterales llamados también triadas, aunque el estudio de las redes de conocimiento supone inteligencias, sabidurías y emociones compartidas por lo que se les llama universos o unimodales que los distingue de otras redes, grafos o nodos multidiversos o multimodales (García, 2006).

La sumatoria de todas las relaciones establecidas y las relaciones posibles es conocida como densidad de la red, grafo o nodo. En el caso de una IES 
con institutos, facultades y departamentos estas pueden ser unilaterales si sus estructuras de decisión son horizontales, pero serán bidireccionales si más bien prevalecen jerarquías, aunque la estimación de la influencia de las alianzas en las redes, de estas en los grafos y de estos en los nodos suponga relaciones verticales susceptibles de calcularse como peso de la densidad de las relaciones (García, 2007).

Es así como las relaciones posibles entre alianzas, redes, grafos o nodos se establece por los vínculos entre una organización con respecto a otras semejantes, pero a la inversa el peso direccional se reduce, ya que los convenios propuestos por una organización serán más relevantes que las iniciativas de vinculación de otras semejantes (Sales, Quintero \& Velázquez, 2016). Es decir, que la inteligencia y la emotividad para establecer acuerdos con otras organizaciones supone una maduración paulatina o sabiduría. En contraste, recibir solicitudes de convenios para producir y transferir conocimiento serán considerados indicativos de una organización pasiva.

Sin embargo, la hegemonía de una organización respecto a otras semejantes radica en la sumatoria de sus relaciones, ya que si esta adición es mayor que la obtenida por otras organizaciones, entonces será reconocida como un nodo hegemónico por la cantidad de alianzas y redes que forma académica y profesionalmente (García, 2015).

La sumatoria de esas relaciones posibles adquiere una mayor relevancia si observan las dimensiones de esas relaciones, ya que un convenio de cooperación tecnológica será inferior a un acuerdo de innovación competitiva con respecto a un tercer nodo, el cual podría ser una organización financiera. Es decir, dos instituciones o redes de investigación al competir por el mejoramiento de la calidad de procesos y productos tendrán más valor que aquellas organizaciones o redes cooperativas donde prevalecen acuerdos de transferencia de conocimiento sin un umbral mínimo o máximo de eficiencia, eficacia o efectividad (Escobar, 2014).

No obstante, las redes de conocimiento que abiertamente compiten por financiamiento solo aspiran a una hegemonía provisional antes de ser desplazadas por otras organizaciones más productivas. En cambio, las organizaciones cooperativas y las redes de conocimiento propensas a la colaboración edifican un patrimonio cultural histórico que no solo les dota de prestigio sino, además de reconocimiento en la formación académica o profesional más que en la transformación de su entorno (véase Tabla 3). 
Tabla 3.

Fases de poder e influencia de las organizaciones a partir de sus relaciones coyunturales e históricas

\begin{tabular}{|c|c|c|}
\hline & COYUNTURAL & HISTÓRICA \\
\hline Continuidad & $\begin{array}{l}\text { Las organizaciones complejas establecidas por la emer- } \\
\text { gencia de sus relaciones generan estructuras de poder } \\
\text { con base en el liderazgo de sus talentos, sus atributos } \\
\text { motivacionales y sus estilos de vigilancia y control. }\end{array}$ & $\begin{array}{l}\text { Las organizaciones complejas producen innovaciones } \\
\text { a partir de las que es posible estimar la influencia que } \\
\text { estas pudieron tener en el pasado, la que tienen en el } \\
\text { presente y la que tendrían en el futuro. }\end{array}$ \\
\hline \multirow[t]{2}{*}{ Discrecionalidad } & $\begin{array}{c}\text { Las organizaciones complejas generan liderazgos avocados } \\
\text { a la motivación de sus talentos y la optimización de sus } \\
\text { procesos. }\end{array}$ & $\begin{array}{l}\text { Las organizaciones complejas que adoptan estilos de re- } \\
\text { laciones singulares, configurando capacidades sin tomar } \\
\text { en cuenta las oportunidades posibles. }\end{array}$ \\
\hline & Inteligencia & Sabiduría \\
\hline Densidad relacional & $\begin{array}{l}\text { Las organizaciones inteligentes gestionan, producen y } \\
\text { transfieren conocimiento a partir de la competencia por } \\
\text { los recursos financieros de una tercera organización, sien- } \\
\text { do la sumatoria de sus éxitos su densidad relacional. }\end{array}$ & $\begin{array}{l}\text { Las organizaciones sabias forman talentos o capitales } \\
\text { intelectuales dedicados a la reproducción del conoci- } \\
\text { miento y emotividad, siendo la sumatoria de los recono- } \\
\text { cimientos su densidad relacional, }\end{array}$ \\
\hline Peso dimensional & $\begin{array}{l}\text { Las organizaciones inteligentes establecen una hegemonía } \\
\text { de relaciones de poder a partir de la eficiencia, eficacia y } \\
\text { efectividad de sus procesos y productos. }\end{array}$ & $\begin{array}{l}\text { Las organizaciones sabias transfieren conocimiento } \\
\text { para el bien común, asumiendo que sus alianzas, redes, } \\
\text { grafos, nodos o arcos son parte de un sistema de coope- } \\
\text { ración solidaria. }\end{array}$ \\
\hline
\end{tabular}

Fuente: Adaptada de Carreón et al. (2016)

La complejidad de las organizaciones, en un sentido de capital social y relacional, supone el establecimiento de una coyuntura de poder respecto a una historia de influencia de una organización respecto a sus semejantes y en función de las demandas del entorno, así como de los recursos y las capacidades disponibles (García et al., 2012).

Se trata de una serie de características y atributos organizacionales que distingue a las inteligencias de las sabidurías en su proceso de creación del conocimiento. Valores, normas, símbolos, rituales, autonomía, dialéctica, representación e identidad son ahora subprocesos que distinguen a las dimensiones organizacionales complejas de auto-regulación, disipación, adaptabilidad y dinamismo. A su vez estás distinciones explican las diferencias entre las organizaciones inteligentes respecto a las sabidurías organizacionales (véase Tabla 4).

Tabla 4.

Culturas organizacionales complejas

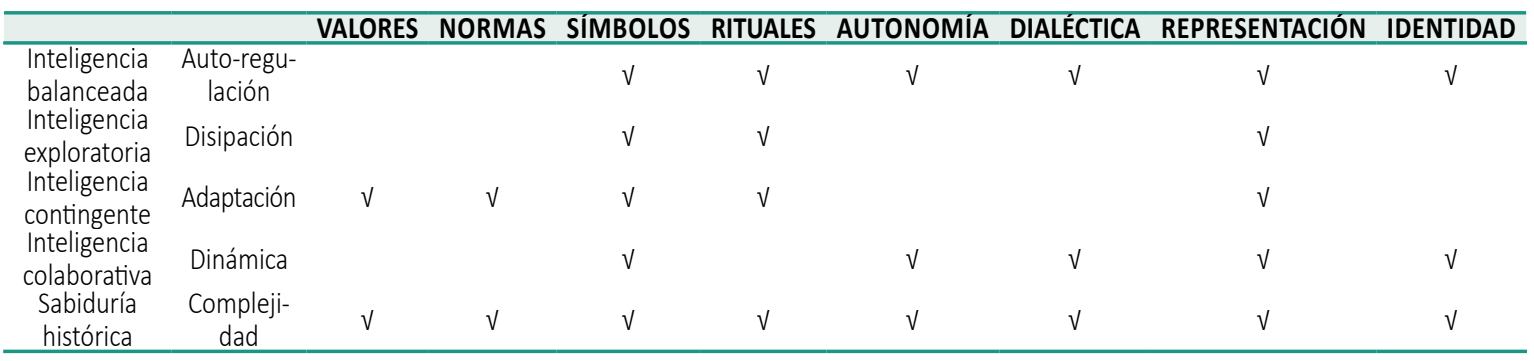

Fuente: Adaptada de Carreón et al. (2016) 
Es así como las organizaciones complejas se distinguen de las demás por su densidad y peso relacional observable en sus convenios o acuerdos de cooperación, producción y competitividad, así como por la edificación de una inteligencia provisoria de una sabiduría histórica y por ende significativa al ser transferida en sus arcos de comunicación y motivación (García, Mejía, Hernández, López \& Salinas, 2015).

En ambos casos se trata de organizaciones inteligentes orientadas hacia la sabiduría, pero la complejidad organizacional radica en la emergencia de sus procesos. Si sus procesos son continuos entonces tenderán a ser coyunturales, pero si son discretos, entonces serán históricos debido al simbolismo que implica sus narrativas y discursos. Es el caso de las automotrices norteamericanas y japonesas. Ford fue hegemónica en cuanto a su producción misma que General Motors optimizó hasta tener el mayor volumen de unidades vendidas, pero fue Toyota quien no solo superó esas ventas sino, además implantó la calidad total en su producción, dotándola de un simbolismo hegemónico (García, Carreón, Hernández \& Salinas, 2016a).

Desde una perspectiva del liderazgo, las organizaciones complejas desarrollan e implementan objetivos, tareas y estrategias centradas en la comunicación multilateral y la motivación híbrida: extrínseca e intrínseca (Vázquez, Barrientos, Quintero \& Velázquez, 2016). En el primer caso se trata de organizaciones dedicadas a producción del conocimiento mediante una inteligencia que las enlaza con otras organizaciones, pero las desvincula internamente (Ortiz \& García, 2008). En el segundo caso, la solidaridad establece un vínculo afectivo y emocional significativo, pero excluyente de otros valores externos. La motivación extrínseca supone un liderazgo transformacional y la motivación intrínseca, un liderazgo tradicional (Pérez, Valdés \& García, 2017).

En cuanto a las organizaciones que desarrollan una comunicación multilateral a través de liderazgos tradicionales frente a organizaciones complejas que desarrollan liderazgos emergentes y transformacionales (García, 2004). Ambas son resultado de las demandas externas en función de los recursos internos, pero al ser estos activos intangibles suponen procesos latentes que solo es posible inferir a partir de indicadores de empatía, compromiso, emprendimiento, cooperación, productividad, competitividad, satisfacción y felicidad (Pérez et al., 2016).

Las organizaciones complejas edifican una identidad que consiste en las posibilidades de elección de un nodo respecto a otros (García, 2005). Es el caso de las redes sociales que promueven la interrelación entre sus usuarios, pero sobre todo, difunden la posibilidad de entablar contacto con otros 
usuarios desconocidos (García, Carreón, Sandoval, Bustos \& Aguilar, 2016b). Empero, el usuario debe establecer criterios de selección y categorización de información con la finalidad de conservar o transformar el grafo al que pertenecen, o bien, reconstruir el nodo y los arcos que le permitieron formarse como un intangible o capital intelectual de la organización (véase Tabla 5).

Tabla 5.

Redes organizacionales complejas

\begin{tabular}{|c|c|c|c|}
\hline & GRAFO & NODO & ARCO \\
\hline Categorización & $\begin{array}{l}\text { Culturas de identificación que } \\
\text { generalizan o diferencian a sus } \\
\text { nodos con respecto a estructuras } \\
\text { de oportunidades y capacidades. }\end{array}$ & $\begin{array}{l}\text { Organizaciones con procesos de identifi- } \\
\text { cación en las que liderazgos y talentos se } \\
\text { desarrollan en función de la evitación de } \\
\text { contacto, la superficialidad de relaciones o } \\
\text { la intimidad vinculadora. }\end{array}$ & $\begin{array}{c}\text { Acuerdos de identificación que } \\
\text { establecen relaciones de evitación, } \\
\text { superficialidad o intimidad a partir de } \\
\text { la pertenencia esperada de nodos a } \\
\text { un grafo. }\end{array}$ \\
\hline Identidad & $\begin{array}{l}\text { Culturas de pertenencia donde } \\
\text { los grafos son establecidos por } \\
\text { relaciones tácitas más implícitas. }\end{array}$ & $\begin{array}{c}\text { Organizaciones con sentido de pertenencia } \\
\text { en las que las relaciones se establecen } \\
\text { conforme a las expectativas de pertenecer } \\
\text { a un grafo. }\end{array}$ & $\begin{array}{c}\text { Convenios de pertenencia en los } \\
\text { que las relaciones se circunscriben a } \\
\text { nodos unimodales. }\end{array}$ \\
\hline Liderazgo & $\begin{array}{c}\text { Culturas supeditadas a la comuni- } \\
\text { cación unilateral y la motivación } \\
\text { unidireccional del líder. }\end{array}$ & $\begin{array}{l}\text { Organizaciones lideradas por talentos } \\
\text { en cuanto a objetivos, tareas y metas, } \\
\text { procesos continuos y discretos inherentes a } \\
\text { inteligencias provisorias. }\end{array}$ & $\begin{array}{l}\text { Pactos de vinculación en función de } \\
\text { las capacidades de talentos más que } \\
\text { de líderes en la gestión, producción y } \\
\text { transferencia de conocimiento. }\end{array}$ \\
\hline
\end{tabular}

Fuente: Adaptada de Carreón et al. (2016)

De este modo, la inteligencia y la sabiduría de las organizaciones destacan como factores determinantes de la gestación, formación y consolidación de las redes de conocimiento sus procesos colaborativos y dimensiones complejas, aunque el estado de la cuestión no ha explicado ni al menos explorado las dimensiones complejas (autorregulación, disipación, adaptación y dinamismo) que la teoría advierte como ejes de las redes colaborativas dedicadas a la creación del conocimiento. Por consiguiente, el contraste de estas dimensiones se ha pospuesto, ya que su establecimiento permitiría explicar la configuración de un sistema de gestión, producción y transferencia de conocimiento, o bien, la predicción de inteligencias colaborativas en contextos educativos o escenarios pedagógicos como las IES en general y las universidades públicas en particular dada su diversidad de datos, recursos y talentos.

Más aún, las políticas educativas centradas en la evaluación, acreditación y certificación de la calidad de los procesos y los productos académicos suponen la gestación de una inteligencia colectiva y una sabiduría de masas que se reflejaría en la conformación de alianzas estratégicas entre IES mediante la formación y consolidación de redes de conocimiento dedicadas a la gestión, producción y transferencia de capital intelectual. 
Más específicamente, esas redes de conocimiento que se gestan ante las políticas evaluativas de la calidad educativa se podrían observar a partir del aprendizaje establecido antes y después de la implementación de los programas de evaluación, acreditación y certificación en una IES del centro de México.

Formulación: ¿En el marco de las políticas educativas centradas en la evaluación, acreditación y certificación de la calidad de sus procesos y sus productos, los conceptos de inteligencias colectivas, sabidurías históricas, alianzas estratégicas, redes de conocimiento, grafos de diversificación, nodos de capitales y arcos de información explicarán la complejidad de una IES del centro de México considerando sus grados de aprendizaje de adaptabilidad, autorregulación, disipación y dinamismo frente a las políticas estatales mediante el análisis de sus capas de entrada, ocultas y salientes?

Hipótesis nula: La teoría de las inteligencias, sabidurías, redes, grafos, nodos, capitales y arcos al explicar fehacientemente la complejidad de organizaciones en distintas latitudes, contextos y escenarios predecirá este fenómeno en la IES del centro de México, evidenciando sus grados de aprendizaje (diferencias entre capas de datos entrantes, ocultos y salientes) respecto a cuatro dimensiones: autorregulación, disipación, adaptabilidad y dinamismo.

Hipótesis alterna: No obstante que la teoría de las inteligencias, sabidurías, redes, grafos, nodos, capitales y arcos ha demostrado la prevalencia de la complejidad en organizaciones de las que emergen dimensiones como la adaptabilidad, la disipación, la autorregulación y el dinamismo, será la especificidad de su contexto y la particularidad de sus actores los que contravengan los conceptos esgrimidos en la revisión de la literatura.

\section{MÉTODO}

\subsection{Diseño}

Se llevó a cabo un estudio no experimental, transversal y exploratorio. En virtud de que los estudios de redes complejas de conocimiento son escasos, el diseño se orientó a la contrastación de la hipótesis nula relativa a cuatro dimensiones cuyas diferencias pueden ser observadas con la técnica de redes neuronales.

\subsection{Participantes}

Se realizó una selección no probabilística de 300 administrativos, estudiantes y docentes de una universidad pública del Edomex. 
El $67 \%$ son mujeres y el $33 \%$ hombres.

El 59\% mencionó tener entre 18 y 22 años ( $M=21,34$; $D E=0,12)$, el $20 \%$ declaró tener entre 22 y 29 años $(M=25,23$; $D E=0,25)$, el restante $21 \%$ señaló una edad superior a 29 años ( $M=33,12 ; D E=0,32)$.

El 33\% declaró tener estudios universitarios no terminados, el 32\% cuenta con estudios superiores terminados de licenciatura, el $20 \%$ con estudios de maestría y $15 \%$ con estudios de doctorado.

El 32\% declaró ingresos mensuales familiares inferiores a 3.500 pesos $(\mathrm{M}=$ 3.254; $D E=21,23)$, el $55 \%$ dijo que su familia ingresó entre 3.500 y 7.000 pesos al mes ( $M=4.562 ; D E=234,12)$ y el restante $13 \%$ señaló que su familia ingreso en el último mes más de 7.000 pesos $(M=8712 ; D E=243,14)$.

El $66 \%$ declaró estar en soltería, el $20 \%$ en unión libre y el $14 \%$ contrajo matrimonio.

\subsection{Instrumentos}

Escala de Complejidad Organizacional de García et al., (2016), la cual incluye cuatro dimensiones relativas a la autorregulación, disipación, adaptación y dinamismo. Cada ítem se contesta con alguna de cinco opciones que van desde 0 = nada de acuerdo hasta 5 = "muy de acuerdo".

\subsection{Procedimiento}

A partir de una investigación documental, exploratoria y retrospectiva, considerando el periodo que va de 2010 a 2017, se realizó una selección no probabilística de fuentes primarias o artículos de investigación publicados en revistas indexadas a repositorios nacionales como Latindex y Redalyc. Una vez seleccionados los instrumentos, se procedió a recopilar los reactivos para su evaluación por parte de jueces expertos en la materia con grado de doctorado en ciencias de la educación y experiencia comprobable en investigación de capital intelectual, inteligencia organizacional y redes de conocimiento (véase Anexo A).

Se utilizó la técnica Delphi, la cual estriba en la selección de diez jueces expertos y la conformación de un panel de discusión para la homogeneización de las palabras incluidas en los reactivos (López, 2018). Se garantizó la confidencialidad de las respuestas a la encuesta por escrito, informándoles que los resultados de la investigación no afectarían su estatus académico o laboral 
(véase Anexo B). Las encuestas se realizaron en el vestíbulo de la biblioteca de la universidad. La información fue procesada en el Paquete Estadístico para Ciencias Sociales (SPSS por sus siglas en inglés) versión 20,0.

\subsection{Análisis de datos}

Se estimaron media, desviación estándar, $\mathrm{KMO}$, prueba de Bartlett, pesos factoriales y pesos de sinapsis para la Escala de Complejidad Organizacional (ECO-16).

Se seleccionaron y codificaron 128 ítems de los cuales se descartaron 36 por haber sido considerados repetidos y de los 92 restantes se marginaron 76 en las pruebas de normalidad estadística: media, desviación estándar, curtosis, sesgo y asimetría.

Los restantes 16 ítems fueron agrupados en el análisis factorial exploratorio de ejes principales con rotación promax, antes de su adecuación y esfericidad.

Se estimó la confiabilidad con el parámetro alfa de Crombach $(0,780)$ para establecer la consistencia del instrumento en otros contextos, escenarios y muestras de estudio. Se estableció la validez con un análisis factorial exploratorio de ejes principales con rotación promax, adecuación y esfericidad.

Una vez establecidos los factores, se procedió a estimar las redes de conocimiento considerando las capas de entradas, las capas ocultas o posibles y las capas salientes de datos. Esa diferencia permitió constatar la hipótesis nula relativa al ajuste de la teoría con respecto a los datos observados.

Se trata de una técnica estadística basada en algoritmos de aprendizaje artificial con la finalidad de observar la complejidad organizacional que es inferida por las asimetrías entre las densidades de relaciones y el peso de los vínculos entre los nodos o sujetos de estudio y sus respuestas o indicadores de sus relaciones. Tal registro y observación evidencia no solo sus dimensiones autorregulativa, disipativa, dinámica o adaptativa sino, además, refleja el grado de optimización de sus recursos o el nivel de innovación de sus procesos implicados en las respuestas a estímulos o las decisiones frente a situaciones contingentes.

Es decir, las redes neuronales aluden a procesos cognitivos que reflejan las inteligencias, sabidurías, redes, grafos, nodos o arcos establecidos en una 
organización frente a las demandas externas y en función de sus recursos internos.

\subsection{Conflictos de interés}

El presente trabajo declara estar exento de cualquier conflicto de interés con respecto a autores, revistas y financiadoras de proyectos de investigación local, nacional, regional o mundial, así como de cualquier literatura impresa o digital que se publicó o se publicará antes y después del artículo en comento.

\section{RESULTADOS}

La Tabla 6 muestra las propiedades estadísticas de las respuestas a los estímulos o ítems aplicados a los 300 administrativos, docentes y estudiantes en relación a cuatro dimensiones complejas: autorregulación, disipación, adaptabilidad y dinamismo.

Es posible observar que el instrumento alcanzó un nivel de consistencia discreto (alfa de 0,780 ), lo cual sugiere que al aplicarse en otros contextos, escenarios y muestras registradas medirá las cuatro dimensiones de un modo similar.

La adecuación y esfericidad $\left[\mathrm{KMO}=0,796 ; \chi^{2}=505,397\right.$ (120gl) $\mathrm{p}=0,000$ ] permitieron la estimación de la validez del instrumento. La autorregulación al explicar el $46 \%$ de la varianza total explicada, evidencia la complejidad de la IES al demostrar que está sujeta a lineamientos institucionales y demandas de su entorno que la obligan a buscar un equilibrio mediante subprocesos de continuidad y discrecionalidad, así como la formación de talentos orientados hacia la inteligencia colectiva más que a la sabiduría.

La autorregulación refiere a una identidad centrada en un liderazgo tradicional que establece una comunicación y motivación unilateral, dándole continuidad a las políticas de evaluación, acreditación y certificación de la calidad de sus procesos y productos más que al emprendimiento y la innovación.

Además, sugiere una apuesta por la conservación histórica de un modo de reproducción del conocimiento más que una propuesta de transformación de sus estructuras y relaciones. Se trata de alianzas estratégicas, redes de conocimiento, grafos institucionales, nodos informativos y arcos de satos circunscritos a la preservación de valores jerárquicos y climas de relaciones tradicionales. 
Tabla 6.

Descriptivos del instrumento

\begin{tabular}{|c|c|c|c|c|c|c|c|}
\hline CÓDIGO & ÍTEMS & M & $\mathrm{DE}$ & F1 & F2 & F3 & F4 \\
\hline \multicolumn{8}{|c|}{ SUBESCALA DE AUTORREGULACIÓN (EQUILIBRIO EMERGENTE DE LAS DIFERENCIAS) } \\
\hline AR1 & $\begin{array}{c}\text { Las diferencias entre objetivos y logros son inexorables al } \\
\text { liderazgo académico }\end{array}$ & 1,40 & 1,773 & $-0,542$ & & & \\
\hline AR2 & $\begin{array}{c}\text { Las vicisitudes entre líderes y seguidores son reflejo de la } \\
\text { universidad }\end{array}$ & 1,87 & 1,306 & 0,985 & & & \\
\hline AR3 & $\begin{array}{c}\text { Las asimetrías entre metas y capacidades son inherentes a la } \\
\text { universidad }\end{array}$ & 1,57 & 1,406 & 0,471 & & & \\
\hline AR4 & $\begin{array}{l}\text { Las diferencias entre necesidades y estrategias indican la } \\
\text { calidad educativa }\end{array}$ & 1,77 & 1,431 & 0,852 & & & \\
\hline \multicolumn{8}{|c|}{ SUBESCALA DE DISIPACIÓN (ORGANIZACIÓN EMERGENTE DEL DESORDEN) } \\
\hline DS1 & Las alianzas reflejan la historia conflictiva de la universidad & 2,77 & 1,995 & & 0,666 & & \\
\hline DS2 & Los acuerdos indican la historia parsimoniosa de la universidad & 0,77 & 1,006 & & $-0,546$ & & \\
\hline DS3 & $\begin{array}{l}\text { Las corresponsabilidades son resultado de los desencuentros } \\
\qquad \text { académicos }\end{array}$ & 3,33 & 2,249 & & 0,843 & & \\
\hline DS4 & Los logros reflejan la historia de fracasos de la universidad & 1,23 & 0,774 & & $-0,883$ & & \\
\hline \multicolumn{8}{|c|}{ SUBESCALA DE ADAPTACIÓN (AJUSTE DE LOS RECURSOS ANTE LAS DEMANDAS) } \\
\hline AD1 & La evaluación educativa activa el compromiso de la universidad & 3,67 & 1,516 & & & 0,926 & \\
\hline AD2 & $\begin{array}{l}\text { La calidad educativa refleja la confianza al interior de la } \\
\text { universidad }\end{array}$ & 2,20 & 1,297 & & & 0,352 & \\
\hline AD3 & $\begin{array}{c}\text { La deserción escolar indica los liderazgos autocráticos de la } \\
\text { universidad }\end{array}$ & 0,30 & 0,466 & & & 0,302 & \\
\hline AD4 & $\begin{array}{c}\text { El rezago educativo es inherente a la cultura autocrática de la } \\
\text { universidad }\end{array}$ & 0,53 & 0,507 & & & $-0,346$ & \\
\hline \multicolumn{8}{|c|}{ SUBESCALA DE DINAMISMO (COLABORACIÓN ANTE OPORTUNIDADES Y RETOS) } \\
\hline DM1 & $\begin{array}{l}\text { El credencialismo es resultado de las políticas de educación de } \\
\text { masas }\end{array}$ & 3,20 & 2,203 & & & & 0,493 \\
\hline $\mathrm{DM} 2$ & $\begin{array}{l}\text { La matrícula educativa es reflejo de las demandas del mercado } \\
\qquad \text { laboral }\end{array}$ & 4,47 & 0,776 & & & & $-0,162$ \\
\hline DM3 & La deserción escolar supone la exclusión social de la educación & 0,70 & 0,466 & & & & 0,355 \\
\hline DM4 & El rezago educativo es indicativo de la competencia humana & 1,50 & 1,834 & & & & 0,308 \\
\hline
\end{tabular}

Esfericidad y Adecuación $\left[\mathrm{KMO}=0,796 \chi^{2}=505,397(120 \mathrm{gl}) \mathrm{p}=\right.$ 0,000 Método de extracción: componentes principales (rotación varimax). F1 = Autorregulación (46\% de la varianza total explicada), F2 = Disipación (16\% de la varianza total explicada), F3 = Adaptabilidad (10\% de la varianza total explicada) y F4 = Dinamismo ( $8 \%$ de la varianza total explicada). Cada ítem se responde eligiendo una opción que va desde $0=$ nada de acuerdo hasta $5=$ muy de acuerdo.

Una vez establecidas las cuatro dimensiones complejas: autorregulación, disipación, adaptabilidad y dinamismo se procedió a estimar la red neuronal, sus capas de entrada, ocultas y de salida para evidenciar el grado de aprendizaje al observar sus diferencias en los algoritmos (véase Tabla 7). 
Tabla 7.

Caracterización de la red neuronal

\begin{tabular}{|c|c|c|c|}
\hline \multirow{5}{*}{ CAPA DE ENTRADA } & \multirow{4}{*}{ Factores } & 1 & Autorregulación \\
\hline & & 2 & Disipación \\
\hline & & 3 & Adaptación \\
\hline & & 4 & Dinamismo \\
\hline & Número de unidades ${ }^{\text {a }}$ & & 33 \\
\hline \multirow{3}{*}{ CAPAS OCULTAS } & Número de capas ocultas & & 1 \\
\hline & Número de unidades en la capa oculta $1^{\mathrm{a}}$ & & 10 \\
\hline & Función de activación & & Tangente hiperbólica \\
\hline \multirow{5}{*}{ CAPA DE SALIDA } & Variables dependientes & 1 & Complejidad \\
\hline & Número de unidades & & 1 \\
\hline & Método de cambio de escala para las dependientes de escala & & Estandarizados \\
\hline & Función de activación & & Identidad \\
\hline & Función de error & & Suma de cuadrados \\
\hline
\end{tabular}

El peso neuronal de cada dimensión sugiere que es la disipación del factor que explica el aprendizaje del grafo (véase Tabla 8). Se trata de una red con una capa de entrada de datos de 8 a 11 unidades, con una capa oculta de tres datos (peso $=0,633$ ) y de esta misma con una única capa de salida $(-0,586)$.

Es decir, la complejidad organizacional radica en la disipación de sus datos informativos, los cuales denotan un aprendizaje negativo inferido por la diferencia negativa entre la capa de salida con respecto a la capa entrante y oculta.

Esto quiere decir que la inteligencia colectiva que el capital intelectual de la organización no se circunscribe a lineamientos institucionales o atributos de liderazgo tradicional, así como a una comunicación autocrática o una motivación extrínseca.

Más bien se trata de una red de conocimiento enfocada en el emprendimiento, aunque estos no corresponden con innovaciones que sustenten un aprendizaje significativo ni con propuestas latentes de liderazgo transformacional o talento emergente que puedan generar un conocimiento más que optimizar los recursos internos.

Tabla 8.

Estimación de la red neuronal

\begin{tabular}{|c|c|c|c|c|c|c|c|c|c|c|}
\hline \multirow{3}{*}{$\begin{array}{l}\text { PREDICTOR } \\
\text { CE }\end{array}$} & \multicolumn{10}{|c|}{ PRONOSTICADO } \\
\hline & \multicolumn{10}{|c|}{$\mathrm{CO}$} \\
\hline & $H(1: 1)$ & $H(1: 2)$ & $H(1: 3)$ & $H(1: 4)$ & $H(1: 5)$ & $H(1: 6)$ & $H(1: 7)$ & $H(1: 8)$ & $H(1: 9)$ & $H(1: 10)$ \\
\hline (Sesgo) & 0,247 & 0,229 & 0,127 & 0,309 & $-0,124$ & 0,471 & 0,157 & $-0,271$ & $-0,242$ & 0,295 \\
\hline$[A R=1,00]$ & $-0,290$ & 0,492 & $-0,221$ & 0,390 & $-0,414$ & 0,401 & 0,361 & $-0,212$ & $-0,279$ & $-0,335$ \\
\hline
\end{tabular}




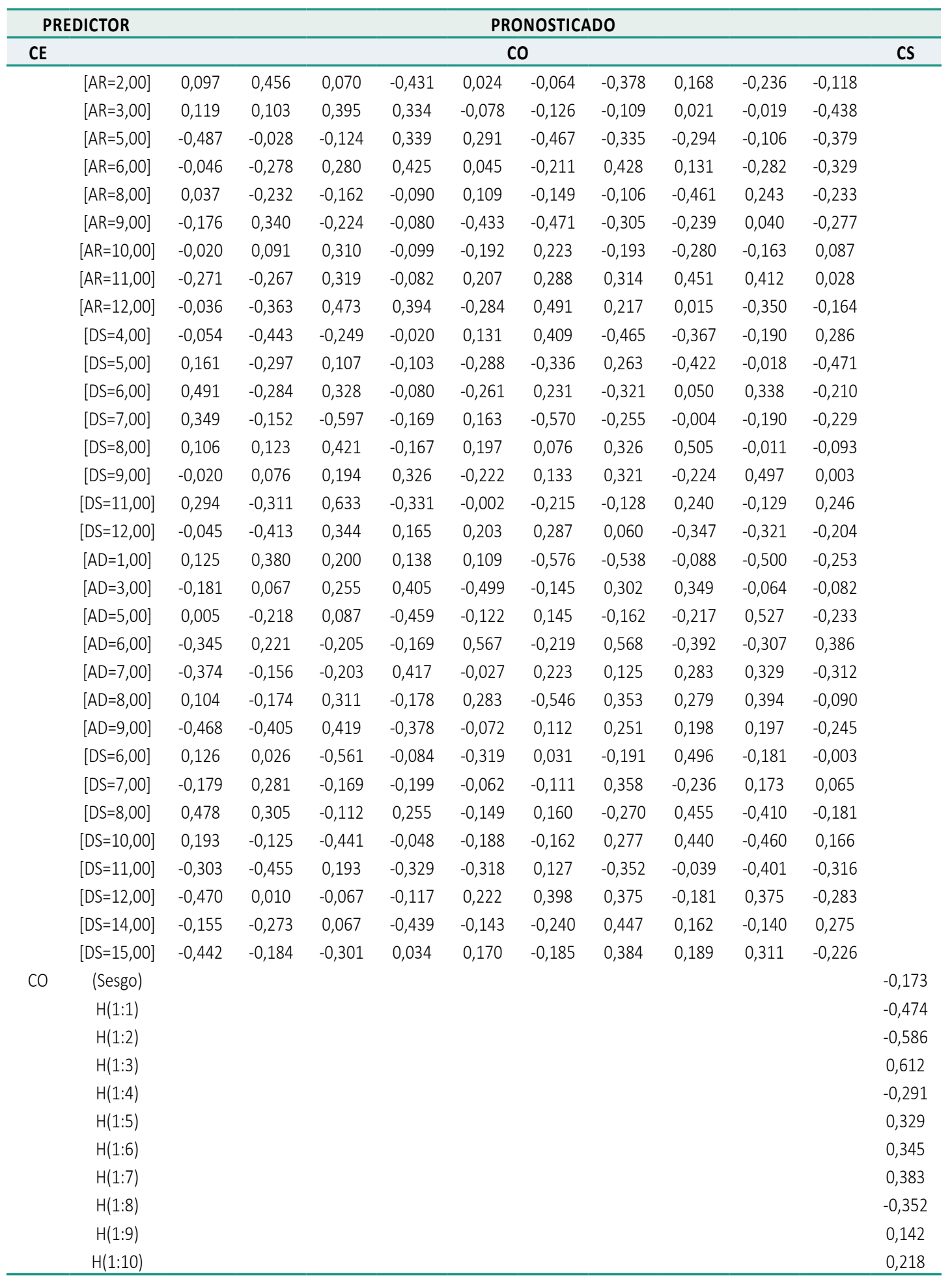

$\mathrm{CE}=$ Capa de Entrada, $\mathrm{CO}=$ Capa Oculta, $\mathrm{CS}=$ Capa de Salida, $\mathrm{AR}=$ Autorregulación, DS = Disipación, $A D=$ Adaptación, $D M=$ Dinamismo 


\section{DISCUSIÓN}

El aporte del presente trabajo al estado de la cuestión radica en el establecimiento de la confiabilidad, la validez y el aprendizaje de redes de conocimiento enfocadas en la colaboración autorregulada, disipada, adaptada y dinámica, pero el tipo de estudio no experimental, el tipo de selección muestral no probabilística y el tipo de análisis factorial exploratorio limitan los resultados a la muestra de estudio.

Sin embargo, el estudio de Pereda, López y González (2018) en el que destacan la inexistencia de la inteligencia colectiva, la cual sugieren forjarla desde un liderazgo transformacional con un grado de inteligencia, comunicación y motivación emocional contraviene el supuesto de redes de conocimiento centradas en el aprendizaje relacional.

Pues bien, en el presente trabajo se destaca la conformación de una estructura factorial relativa al aprendizaje informacional. Se trata de un modelo que explica la gestión, producción y transferencia del conocimiento en una modalidad de redes colaborativas, aunque el estilo del liderazgo y sus atributos como la motivación unidireccional y la comunicación unilateral explicarían un porcentaje de esa varianza, incrementando el poder explicativo del modelo de redes de conocimiento.

En ese mismo sentido, Hernández (2018) demostró que el entorno sociodemográfico y socioeconómico incide sobre la autoeficacia académica, la cual antecede a la autoeficacia colectiva. Se trata de una inteligencia centrada en los atributos personales circunscritos a habilidades y conocimientos que pueden surgir de la interrelación con grupos, pero en esencia es una capacidad adquirida del autoaprendizaje.

En contraste, el presente trabajo demostró que más acordes a las redes de conocimiento son la disipación, la autorregulación y el dinamismo, aunque la adaptabilidad podría estar vinculada a la autoeficacia ya que se trata de un autoaprendizaje anterior y posterior a un evento de riesgo.

Sin embargo, el aprendizaje colaborativo supone un esquema de valores compartidos que necesariamente generan una interdependencia al interior de los grupos. Krichesky y Murillo (2018) entrevistaron a profundidad a docentes para evidenciar que la coordinación en tanto indicador de la colaboración no construye objetivos, tareas y metas comunes como es el caso de la interdisciplinar. 
En el presente estudio, la colaboración es parte del dinamismo que refleja una organización compleja como las redes de conocimiento. Es en ese sentido que la coordinación sería un indicador de la dinámica inteligente, pero la interdisciplinar reflejaría la complejidad que supone el procesamiento de información en una red de conocimiento.

Los estudios de la complejidad organizacional y de las redes de conocimiento advierten que los procesos de aprendizaje suponen una instancia latente que correspondería con una instancia manifiesta. En este sentido, la complejidad referiría a los procesos de aprendizaje y conocimiento implícito que solo la sistematización laboral concede, pero sería una complejidad manifiesta si tal procesamiento de información, elaboración e implementación de estrategias se establecen en las tareas. El presente trabajo ha encontrado una prevalencia del aprendizaje centrado en la disipación de la información y el conocimiento más que la autorregulación, la adaptación o el dinamismo. Esto es así porque las políticas de calidad educativa parecen diseminarse asimétricamente entre docentes, estudiantes y administrativos, ya que la red de conocimiento que construyen parece emerger de la diversidad de aportes y la multiplicidad de funciones de sus integrantes más que de un sistema de gestión, producción y transferencia de líderes hacia talentos.

Carreón, Hernández, Quintero y García (2017) demostraron que si bien las IES ajustan sus capacidades a las políticas de evaluación, acreditación y certificación tienden a la innovación al asumir que la calidad de los procesos y los productos son un requerimiento para la provisión de fondos. En esa dinámica, las IES se encuentran en un proceso que va del institucionalismo a la gobernanza o gestión consensuada de la producción y la transferencia de conocimiento.

En el mismo sentido, el presente trabajo ha demostrado que la disipación en tanto indicador de la gestión, producción y transferencia del conocimiento explica una dimensión de su cultura de éxito encaminada más como una estrategia de innovación que como una respuesta a la política educativa.

García, Bustos y Carreón (2017) advierten que el proceso contrario al establecimiento de una red de conocimiento estaría en la gestión, producción y transferencia de estigmas que, en el caso de administrativos, no solo inhiben la gestión del conocimiento sino además lo reducen a su mínima expresión al cancelar el clima de colaboración e innovación necesario para la producción y la transferencia de conocimiento de docentes a estudiantes. 
En el presente trabajo, la disipación no solo explicaría la cultura organizacional de la red de conocimiento sino, además explicaría cómo el estigma subyace en culturas laborales más autoritarias que democráticas, distinguibles por sus grados de control en los procesos y la producción.

Carreón et al. (2017) demostraron que el clima organizacional de una red de conocimiento, indicado el clima de relaciones, apoyos, innovaciones y metas refleja la incidencia de las políticas de calidad educativa sobre la dinámica colaborativa de una IES. Es decir que, el institucionalismo estatal, cercano a una cultura autoritaria más que democrática, propicia la colaboración y la orienta hacia el éxito en la evaluación, acreditación y certificación, pero limita su clima de innovaciones, reduciendo con ello la importancia de la disipación en las funciones como en las estrategias de gestión, producción y transferencia del conocimiento.

Se trata de una encrucijada, la cual por una parte estriba en el ajuste de las capacidades a los requerimientos estatales a fin de poder alcanzar la acreditación y certificación, pero en otro sentido consiste en la innovación de los procesos como ventaja competitiva de la IES respecto a sus competidoras en la captación de fondos.

En la IES del presente estudio, esta ha logrado la calidad de sus procesos ajustando sus capacidades a los requerimientos estatales, a la vez que está generando un clima de innovación centrado en la disipación de sus procesos y productos, estrategias y funciones.

Por consiguiente, es recomendable incorporar el clima organizacional y sus indicadores de colaboración, innovación, tareas, metas y relaciones en el modelo de red de conocimiento, enfocado en la complejidad del aprendizaje disipativo organizacional. Ello supone la observación de dos procesos: uno institucional enfocado en el clima de tareas y metas con respecto a la política de calidad educativa y otro interinstitucional centrado en un clima de emprendimiento e innovación relativa a las contingencias del entorno y las capacidades de la organización.

\section{CONCLUSIÓN}

El aporte del presente trabajo al estado del conocimiento estriba en la confiabilidad, la validez y la estructura de red neuronal artificial relativa a la complejidad organizacional. Los cuatro factores encontrados -autorregulación, disipación, adaptabilidad y dinamismo- corresponden a una estructura de 
relaciones posibles que explican la complejidad organizacional, aunque es el factor de autorregulación el que explica el mayor porcentaje de la varianza y es el factor de la disipación en que evidenció el único aprendizaje de un modo negativo entre los datos entrantes, ocultos y salientes.

Tales hallazgos corresponden a la tipología de una organización con más sabiduría que inteligencia dado que procura el equilibrio entre las demandas del entorno con respecto a los recursos y las capacidades internas, así como la formación de talentos para la optimización de recursos más que la innovación de procesos.

Se trata de una IES centrada en la verticalidad de sus decisiones que se diseminan desde un liderazgo autocrático ajustado al institucionalismo de sus procesos, una comunicación y motivación unilateral con subprocesos discrecionales, así como un capital intelectual limitado por el clima de relaciones.

En el marco de las políticas educativas de evaluación, acreditación y certificación de la calidad de procesos y productos la IES de estudio parece orientarse por valores cooperativos que resultan de relaciones empáticas y compromisos laborales. Esto es así porque su aprendizaje radica en una historicidad de lineamientos institucionales y la construcción de una identidad consistente en elecciones ajustadas a la preservación de la estructura jerárquica y la cultura autocrática.

Financiamiento: Artículo derivado del proyecto: “Gobernanza de las Instituciones de Educación Superior y las Redes de Conocimiento en el Estado de México", financiado por la UNAM-DGAPA-PAPIIT, número de registro IN3055216

Agradecimientos: A la junta directiva de la Red Académica Transdisciplinar: Dr. Javier Carreón Guillén, Dr. José Marcos Bustos Aguayo, Dra. Margarita Juárez Nájera, Dra. María Luisa Quintero Soto, Dr. Francisco Rubén Sandoval Vázquez, Dra. Eréndira Fierro Moreno, Dr. Christian Bucio Pacheco, Dr. Eleazar Villegas González, Dr. Carlos Islas Moreno, Dr. José Sócrates López Pérez por el financiamiento de la investigación.

\section{REFERENCIAS}

Acar, Z., \& Acar, P. (2014). Organizational culture types and their effects on organizational performance in Turkish hospitals. Emerging Markets Journal, 3(3), 1-15. https://doi.org/10.5195/emaj.2014.47

Aguilar, J. A., Bautista, M., García, C., Hernández, G., Sandoval, F. R., Pérez, G. \& Valdés, O. (2016). Confiabilidad y validez de un instrumento que mide el institucionalismo educativo en una universidad pública del Estado de México. Investigación Académica Sin Frontera, 9(22), 1-16. http://revistainvestigacionacademicasin- 
frontera.com/inicio/wp-content/uploads/2014/02/9.-CONFIABILIDAD-Y-VALIDEZ-DE-UN-INSTRUMENTO-Cruz-Garcia-Larios.pdf

Anicijevic, N. (2013). The mutual impact of organizational culture and estructure. Economic Annals, 58(198), 35-60. https://doi.org/10.2298/EKA1398035J

Carreón, J. (2016). Desarrollo humano: Gobernanza y emprendimiento social. México: UNAM-ENTS.

Carreón, J., Hernández, J., Castillo, M. B., \& García, C. (2015). Contraste de un modelo de red intencional. Alternativas en psicología, 1, 50-65. http://alternativas. me/22-numero-33-agosto-2015-enero-2016/101-contraste-de-un-modelo-dered-intencional

Carreón, J., Hernández, J., García, C., \& Bustos, J. M. (2017). Factores perceptuales del neoliberalismo educativo en una IES del centro de México. Revista de Trabajo Social, 15, 50-57. http://www.revistatsudec.cl/category/volumen-15-nuevo

Carreón, J., Hernández, J., Morales, M. L., \& García, C. (2014). Discursos en torno a una red de formación profesional. Taltemoani, 16, 104-133. http://www.eumed. net/rev/tlatemoani/16/emprendimiento.html

Carreón, J., Hernández, J., Quintero, M. L. \& García, C. (2017). Confiabilidad y validez de un instrumento que mide la colaboración organizacional en una universidad pública de Huehuetoca (centro de México). Invurnus, 12(2), 9-17. http://www. invurnus. uson. $m x /$ articulo.php?art $=133 \&$ rev $=25$

Carreón, J., Hernández, J., Quintero, M. L. \& García, C. (2016). Confiabilidad y validez de un instrumento que mide la inteligencia organizacional en una universidad del centro de México. Tlamati, 7(2), 41-47. http://www.invurnus.uson.mx/articulo. php?art=55\&rev=13

Carreón, J., Hernández, J., Quintero, M. L., García, C. \& Mejía, S. (2016). Redes de conocimiento en torno a la complejidad organizacional: Aprendizaje de la autoregulación, disipación, adaptabilidad y dinamismo ante los cambios. Prospectivas en Psicología, 2(2), 57-70 URL: http://ri.uaemex.mx/bitstream/ handle/20.500.11799/65918/redes-de-conocimiento-en-torno-a-la-complejidad-organizacional.pdf?sequence $=1$ \&isAllowed $=y$

Cruz, O., Arroyo, P., \& Marmolejo, J. (2016). Innovaciones tecnológicas en la logística: gestión de inventarios, sistemas de información y terciarización de operaciones. En M. Quintero, J. Sales \& E. Velázquez (Coord.), Innovación y tecnología retos para su aplicación práctica en las empresas. (pp. 165-178). México: Miguel Ángel Porrúa-Uaemex.

Escobar, R. (2014). Redes neuronales, procesos cognoscitivos y análisis de la conducta. Revista Internacional de Conductismo, 2(1), 23-43. http://conductual.com/ content/redes-neuronales-procesos-cognoscitivos-y-analisis-de-la-conducta

Erfani, M. \& Jafari, P. (2013). A model for organizational intelligence in Islamic Azad University. Mathematical Education Trends \& Research, 1, 1-10 https://doi. org/10.5899/2013/metr-00021

García, C. (2004). Una modelación de los determinantes de la eficacia organizacional. Revista Internacional de Psicología, 5(1), 1-12. http://revistapsicologia.org/index. php/revista/article/viewFile/27/24

García, C. (2005). Un programa de desarrollo educativo. Educación y Desarrollo, 19, 1-12. http://www.cucs.udg.mx/revistas/edu_desarrollo/anterioresdetalle. php?n=4

García, C. (2006). Un modelo de empresa universidad. Ciencias Sociales, 3(2), 39-47. http://www.funlam.edu.co/revistas/index.php/RCCS/issue/archive 
García, C. (2007). Un programa de desarrollo organizacional. Educación y Futuro Digital, 26, 1-11. https://cesdonbosco.com/numeros-publicados/educacion-y-futuro-digital.html

García, C. (2015). La red de conocimiento en una universidad con sistema de prácticas profesionales y servicio social tecnológico administrativo. Tlatemoani, 18, 32-55. http://www.eumed.net/rev/tlatemoani/18/identidad.pdf

García, C., Bustos, J. M., \& Carreón, J. (2017). Dimensiones exploratorias del estigma social y laboral. Un estudio Delphi con estudiantes de pregrado. Eureka, 14 (1), 55-68. http://psicoeureka.com.py/sites/default/files/articulos/eureka-14-1-11. pdf

García, C., Carreón, J., Hernández, J., Bautista, M., \& Méndez, A. (2012). Modelamiento de variables socio psico organizacionales a partir de una revisión del estado del arte. Revista de Trabajo Social, 28, 13-69. https://revistas.upb.edu.co/ index.php/trabajosocial/article/view/2300/2052

García, C., Carreón, J., Hernández, J., \& Salinas, R. (2016a). Gobernanza de los actores y redes de innovación tecnológica. En M. Quintero, J. Sales, \& E. Velázquez (Coord.), Innovación y tecnología retos para su aplicación práctica en las empresas. (pp. 79-94). México: Miguel Ángel Porrúa-Uaemex.

García, C., Carreón, J., Sandoval, F. J., Bustos, J. M. \& Aguilar, J. A. (2016b). Estructura de la cultura laboral en una institución de promoción de la salud pública. Arequipa, 6(1), 291-304. http://www.camara-arequipa.org.pe/?q=publicaciones/ revista-institucional

García, C., Mejía, S., Hernández, J., López, S., \& Salinas, R. (2015). Confiabilidad y validez de un instrumento que mide la cultura organizacional relativa al institucionalismo educativo. Cuadernos Hispanoamericanos de Psicología, 15(1), 42-52. https://dialnet.unirioja.es/servlet/articulo?codigo=5559769

González, F., \& Váttimo, S. (2012). Procesos de inteligencia colectiva y colaborativa en el marco de las tecnologías web 2,0. Conceptos, problemas y aplicaciones. Anuario de Investigaciones, 19, 273-281. http://www.scielo.org.ar/scielo.php?script=sci_arttext\&pid=S1851-16862012000200035

Hasegawa, H. (2003). Non-native and native speaker theacher's perception of a team-teaching approach: Case of the Jet programme. International Journal of Language Society and Culture, 26, 42-54. http://citeseerx.ist.psu.edu/viewdoc/ download?doi=10.1.1.575.9185\&rep=rep1\&type $=$ pdf

Hernández, A., \& Valencia, R. (2016). Instrumentos de innovación: las redes sociales en la internalización de las micro, pequeñas y medianas empresas mexicanas. En M. Quintero, J. Sales \& E. Velázquez (Coord.), Innovación y tecnología retos para su aplicación práctica en las empresas. (pp. 47-66). México: Miguel Ángel Porrúa-Uaemex.

Hernández, L. F. (2018). Perfil sociodemográfico y académico en estudiantes universitarios respecto a su auto-eficacia académica percibida. Psicogente, 21(39), 35-49. https://doi.org/10.17081/psico.21.39.2820

Krichesky, G. \& Murillo, F. J. (2018). La colaboración docente como factor de aprendizaje y promotor de mejora en estudios de casos. Educación XXI, 21(1), 35-55. DOI: https://doi.org/10.5944/educXX1.15080

Lévy, P. (2004). Inteligencia colectiva. Por una antropología del ciberespacio. Washington: OPS. http://inteligenciacolectiva.bvsalud.org/public/documents/ pdf/es/inteligenciaColectiva.pdf

López, E. (2018). El método Delphi en la investigación actual en educación. Una revisión teórica y metodológica. Educación XXI, 21(1), 17-40. http://revistas. uned.es/index.php/educacionXX1/article/viewFile/20169/16710 
Mendoza, E., Ramírez, L., \& Atriano, R. (2016). Uso de los medios y las tecnologías en la creación de un sistema de innovación para el bien común. En M. Quintero, J. Sales, \& E. Velázquez (Coord.), Innovación y tecnología retos para su aplicación práctica en las empresas. (pp. 95-114). México: Miguel Ángel Porrúa-Uaemex.

Omotayo, O., \& Adenike, A. (2013). Impact of organizational culture on human resource practices: a study of selected Nigerian private universities. Journal of Competitiveness, 5(4), 115-133. https://www.cjournal.cz/index.php?hid=clanek\&cid $=154$

Ortiz, P. \& García, C. (2008). Estudio sobre clima y satisfacción laboral en una empresa comercializadora. Psicología para América Latina, 13, 1-36. http://pepsic.bvsalud. org/scielo.php?script=sci_arttext\&pid=S1870-350X2008000200017

Pereda, F. J., López, T. \& González, F. (2018). Inteligencia emocional como habilidad directiva. Estudio aplicado en los municipios de la provincia de Córdoba, España. Noésis, 27 (53), 98-120. http://erevistas.uacj.mx/ojs/index.php/noesis/article/ view/1077

Pérez, G., Valdés, O. \& García, C. (2017). Determinantes del habitus académico a partir de la gestión del conocimiento. Margen, 85, 1-12. https://www.margen. org/suscri/margen85/oscarva_85.pdf

Pérez, M. I., Carreón, J., Quintero, M. L., Bucio, C., García, C., \& Aguilar, J. A. (2016). La agenda institucionalista y la gestión del conocimiento: Especificación de un modelo de emprendimiento innovador. Kayros, 20(38), 1-9. https://www.revistakairos.org/la-agenda-institucionalista-y-la-gestion-del-conocimiento-especificacion-de-un-modelo-de-emprendimiento-innovador/

Quintero, M., Velázquez, E., Sales, J., \& Padilla, S. (2016). Una revisión del estado del arte sobre pymes. ¿Y los estudios de innovación? En M. Quintero, J. Sales \& E. Velázquez (Coord.), Innovación y tecnología retos para su aplicación práctica en las empresas. (pp. 31-43). México: Miguel Ángel Porrúa-Uaemex.

Robles, C., Alviter, L., Ortega, A., \& Martínez, E. (2016). Cultura de calidad e innovación en la microempresa. En M. Quintero, J. Sales \& E. Velázquez (Coord.), Innovación y tecnología retos para su aplicación práctica en las empresas. (pp. 11-30). México: Miguel Ángel Porrúa-Uaemex.

Saansongu, E., \& Ngutor, D. (2012). The influence of corporate cultura of employee commitment to the organization. International Journal of Business and Management, 7(22), 1-8. https://pdfs.semanticscholar.org/2603/db49aedaa81bbc726cd1e8349c6fb3751185.pdf

Saleh, M., Rahimi, F. \& Amirnejad, E. (2015). The impact of organizational intelligence and its components on the competitive adventage of all the branches of Khuzestan Sina bank. Applied Research in Science \& Technology, 36(3), 402-408 URL: http://citeseerx.ist.psu.edu/viewdoc/download?doi=10.1.1.1021.7009\&re$\mathrm{p}=$ rep1\&type $=$ pdf

Sales, J., Quintero, M., \& Velázquez, E. (2016). Adaptación versus innovación: la formación de distritos industriales a partir de comunidades campesinas. Santa Cruz Atizapan y Chiconcuac. En M. Quintero, J. Sales \& E. Velázquez (Coord.), Innovación y tecnología retos para su aplicación práctica en las empresas. (pp. 181-199). México: Miguel Ángel Porrúa-Uaemex.

Surowiecky, J. (2005). Cien mejor que uno. Barcelona: Urano. https://urano.blob. core.windows.net/share/i_avance/200000002/avance.pdf

Torkamani, B., \& Mahmoudi, M. (2016). Investigation of the relationships beetween organizational intelligence and strategic thinking and determination of its role in creation of a mindful organization: A case study research. Mditerranean Journal of Social Science, 7(3), 79-85 https://doi.org/10.5901/mjss.2016.v7n3s2p79 
Vázquez, C., Barrientos, B., Quintero, M. \& Velázquez, E. (2016). Apoyos gubernamentales para la innovación, tecnología y capacitación de las pequeñas y medianas empresas en México. En M. Quintero, J. Sales \& E. Velázquez (Coord.), Innovación y tecnología retos para su aplicación práctica en las empresas. (pp. 67-78). México: Miguel Ángel Porrúa-Uaemex.

Esta obra está bajo: Creative commons attribution 4.0 international license. El beneficiario de la licencia tiene el derecho de copiar, distribuir, exhibir y representar la obra y hacer obras derivadas siempre y cuando reconozca y cite la obra de la forma especificada por el

\section{(c) BY}




\section{Anexo A}

\section{Escala de Complejidad Organizacional de García (2016)}

Nombre del Juez:

fecha:

La Escala de Complejidad Organizacional ECO-16 está basada en 1) Inventario de Estrategias de Pensamiento (Torkamani \& Mahmoudi, 2016); 2) Escala de Inteligencia Competitiva (Saleh, Rahimi \& Amirnejad, 2015); 3) Cuestionario de Aprendizaje Organizacional (Erfani \& Jafari, 2013). Las escalas originales evalúan rasgos de conocimientos o emociones en un total de 48 ítems. En concreto, las destrezas con las que podemos ser conscientes de nuestras propias emociones, así como de nuestra capacidad para regularlas en escenarios estratégicos y competitivos donde es menester un aprendizaje continuo.

La ECO-16 contiene cuatro dimensiones de cuatro 4 ítems: a) Autoregulación; b) Disipación; c) Adaptación y d) Dinamismo. El objetivo de esta prueba es evaluar cada área en administrativos, docentes y estudiantes de universidades públicas en alianzas estratégicas con organizaciones creadoras del conocimiento.

Instrucción para el juez experto: por favor lea cuidadosamente cada uno de los reactivos y conteste la pregunta ¿Corresponde el ítem a la dimensión que se está planteando?, marque su respuesta con una $(\mathrm{X})$ en la columna correspondiente. Realice sugerencias a los ítems si lo considera pertinente para "salvar" o mejorar el ítem. De antemano, muchas gracias.

\section{Dimensiones}

Autorregulación o equilibrio entre las demandas del entorno organizacional en relación con los recursos de las organizaciones e instituciones aliadas (Carreón, Hernández, Quintero, García \& Mejía, 2016).

\begin{tabular}{|c|c|c|c|c|}
\hline$N / I$ & ÍTEM & sí & NO & SUGERENCIAS \\
\hline 1 & Las diferencias entre objetivos y logros son inexorables al liderazgo académico & & & \\
\hline 2 & Las vicisitudes entre líderes y seguidores son reflejo de la universidad & & & \\
\hline 3 & Las asimetrías entre metas y capacidades son inherentes a la universidad & & & \\
\hline 4 & Las diferencias entre necesidades y estrategias indican la calidad educativa & & & \\
\hline
\end{tabular}


Disipación u organización emergente y colaborativa ante el desequilibrio de demandas externas y recursos internos (Carreón, Hernández, Quintero, García \& Mejía, 2016).

\begin{tabular}{|c|c|c|c|c|}
\hline $\mathrm{N} / \mathrm{I}$ & ÍTEM & sí & NO & SUGERENCIAS \\
\hline 5 & Las alianzas reflejan la historia conflictiva de la universidad & & & \\
\hline 6 & Los acuerdos indican la historia parsimoniosa de la universidad & & & \\
\hline 7 & Las corresponsabilidades son resultado de los desencuentros académicos & & & \\
\hline 8 & Los logros reflejan la historia de fracasos de la universidad & & & \\
\hline
\end{tabular}

Adaptación o ajuste de recursos organizacionales ante las demandas de su entorno (Carreón, Hernández, Quintero, García \& Mejía, 2016)

\begin{tabular}{|c|c|c|c|c|}
\hline $\mathrm{N} / \mathrm{I}$ & ÍTEM & sí & NO & SUGERENCIAS \\
\hline 9 & La evaluación educativa activa el compromiso de la universidad & & & \\
\hline 10 & La calidad educativa refleja la confianza al interior de la universidad & & & \\
\hline 11 & La deserción escolar indica los liderazgos autocráticos de la universidad & & & \\
\hline 12 & $\begin{array}{c}\text { El rezago educativo es inherente a la cultura autocrática de la } \\
\text { universidad }\end{array}$ & & & \\
\hline
\end{tabular}

Dinamismo o colaboración, solidaridad o apoyo ante oportunidades y retos al interior de la organización o provenientes de su entorno (Carreón, Hernández, Quintero, García \& Mejía, 2016)

\begin{tabular}{|c|c|c|c|c|}
\hline $\mathrm{N} / \mathrm{I}$ & ÍTEM & sí & NO & SUGERENCIAS \\
\hline 13 & El credencialismo es resultado de las políticas de educación de masas & & & \\
\hline 14 & La matrícula educativa es reflejo de las demandas del mercado laboral & & & \\
\hline 15 & La deserción escolar supone la exclusión social de la educación & & & \\
\hline 16 & El rezago educativo es indicativo de la competencia humana & & & \\
\hline
\end{tabular}




\section{Anexo B}

Estimado (a):

La Red de Estudios Transdisciplinares está realizando un estudio de opinión acerca de la sabiduría e inteligencia de tu universidad con respecto a oportunidades y retos del mercado laboral. Los resultados de la investigación no afectarán ni negativa ni positivamente tu estatus académico por lo que te pedimos contestes sinceramente a las siguientes aseveraciones.

Tacha la opción que consideres se aproxima a tus expectativas. Por ejemplo, si estas en total desacuerdo con la frase "Al convivir con extranjeros. Disminuiré mi desempeño", entonces deberás tachar la celda correspondiente.

\begin{tabular}{llllll}
\hline 0 & 1 & 2 & 3 & 4 & 5 \\
\hline$X$ & & & & & \\
\hline
\end{tabular}

O bien, si consideras que estás totalmente de acuerdo, entonces deberás tachar la celda debajo del cinco. A continuación, tienes 14 aseveraciones que deberás responder de la misma forma considerando: $0=$ nada de acuerdo, 1 = muy poco de acuerdo, 2 = poco de acuerdo, 3 = ni en desacuerdo ni de acuerdo, 4 = algo de acuerdo y 5 = bastante de acuerdo.

Las diferencias entre objetivos y logros son inexorables al liderazgo académico

Las vicisitudes entre líderes y seguidores son reflejo de la universidad

Las asimetrías entre metas y capacidades son inherentes a la universidad

Las diferencias entre necesidades y estrategias indican la calidad educativa

Las alianzas reflejan la historia conflictiva de la universidad

Los acuerdos indican la historia parsimoniosa de la universidad

Las corresponsabilidades son resultado de los desencuentros académicos

Los logros reflejan la historia de fracasos de la universidad

La evaluación educativa activa el compromiso de la universidad

La calidad educativa refleja la confianza al interior de la universidad

La deserción escolar indica los liderazgos autocráticos de la universidad

El rezago educativo es inherente a la cultura autocrática de la universidad

El credencialismo es resultado de las políticas de educación de masas

La matrícula educativa es reflejo de las demandas del mercado laboral

La deserción escolar supone la exclusión social de la educación

El rezago educativo es indicativo de la competencia humana

\section{Sexo: Masculino ( ) Femenino ( )}

Edad:

Ingreso: 